[J.M.J., Vol. 5, No. 3]

\title{
NATURAL OCCURRENCE OF NUTRITIONAL VARIANTS OF SALMONELLA TYPHI
}

\author{
BY \\ HIDEO FUKUMI, EIKO SAYAMA AND RINTARO NAKAYA \\ The Second Bacteriology Division \\ The National Institute of Health, Tokyo, Japan
}

There have been several papers ${ }^{1-9)}$ concerning the nutritional requirements of Salmonella typhi, and it has become a common knowledge that this organism is able to grow only in the presence of tryptophane as amino acid, but capable of being trained to synthesize this very amino acid. Beside the requirement of tryptophane, this organism was studied on other nutritional behaviours. Burrows ${ }^{7)}$ reported, for example, that there is a variation in certain carbon sources and amino acid requirements among a number of strains of $S$. typhi.

Recently in England, Bacon, Burrows and Yates ${ }^{10)}$ published a paper in which they reported the isolation and characterization of a number of nutritional variants of Salmonella typhi and recorded their virulence in mice. They obtained, indeed, so many nutritional mutants, which were, however, not found in the natural world, but induced artificially.

The present authors examined the nutritional requirements of strains of Salmonella typhi, some of which had been maintained in their laboratory for a long time, but most of them had been isolated recently in the Komagome Hospital for Communicable Diseases*. All of these Salmonella typhi strains tested, except 2 strains, grow well in the following medium:

$\begin{array}{ll}\text { Glucose } & 0.2 \mathrm{~g} \\ \text { Tryptophane } & 0.02 \mathrm{~g} \\ \mathrm{NaCl} & 0.5 \mathrm{~g} \\ \mathrm{MgSO}_{4} & 0.02 \mathrm{~g} \\ \left(\mathrm{NH}_{4}\right) \mathrm{H}_{2} \mathrm{PO}_{4} & 0.1 \mathrm{~g} \\ \mathrm{~K}_{2} \mathrm{HPO}_{4} & 0.1 \mathrm{~g} \\ \text { Aq. dest. } & 100 \mathrm{cc}\end{array}$

* The strains were given to us by the courtesy of Doctor K. Kobari of the Komagome Hospital. 
Therefore, it is clear that these strains of $S$. typhi require only tryptophane as the essential amino acid, growing in glucose, ammonium ion as nitrogen source and other salts, and this is a characteristic nutritional behaviour of Salmonella typhi.

The nutritional behaviours of the two strains not capable of growing in the above mentioned medium are described below:

Strain No. 765 :

The nutritional abnormality of this strain lies in the sulfur metabolism. The strain grows well in the above mentioned basal medium, if this is supplemented with cystin, cystein or $\mathrm{Na}_{2} \mathrm{~S}_{2} \mathrm{O}_{3}$ in 0.02 per cent, therefore it may be concluded that this strain has no capability of synthesizing cystin or cystein from $\mathrm{SO}_{4}$ via $\mathrm{S}_{2} \mathrm{O}_{3}$.

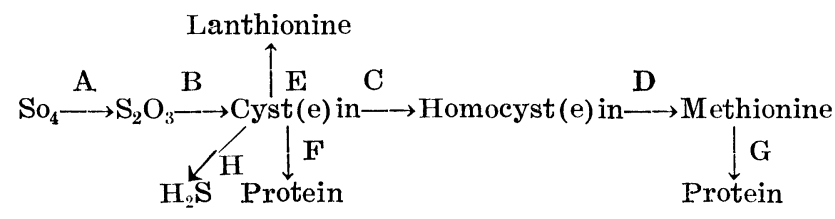

In the above route ${ }^{11)}$, the step $A$ must be blocked in this strain.

The methionine is not able to support the growth of the strain in question in the place of $\mathrm{N}_{2} \mathrm{~S}_{2} \mathrm{O}_{3}$, cystein or cystine, and it may mean that the step $\mathrm{D}$ or $\mathrm{C}$ is not reversible.

This strain was isolated from a patient of typhoid fever a few years ago, whose symptoms were typical and showed no divergence from typical typhoid fever.

Strain No. 786 :

This strain requires pantothenic acid or its component $\beta$-alanine for growth. The amount of the cpmpounds required is $10^{-7} \mathrm{M}$ or more in the case of either pantothenic acid or $\beta$-alanine. At a concentration $10^{-i} \mathrm{M}$ of $\beta$-alanine, the organism grows pretty slowly, namely a long lag period is required, that means that, at the concentration, the conversion of $\beta$-alanine to pantothenic acid takes a pretty long time.

This strain is, too, isolated from a patient of typical typhoid fever, who showed no apparent sign of pantothenic acid defficiency.

The strains No. 765 and No. 786 were measured of their virulence in mice, but there was no abnormality found concerning the virulence, being compared with other ordinary strains, 


\section{SUMMARY}

Among the strains of Salmonella typhi examined, there were found two nutritionally abnormal strains, one of which was blocked on a certain step of sulfur metabolism and the other of which required $\beta$-alanine or pantothenic acid for a growth factor.

\section{REFERENCE}

1) Fildes, P., Gladstone, G. P., and Knight, B. C. J. G.: The nitrogen and vitamin requirements of B. typhosus. Brit. J. Exp. Path., 14, 189, 1933.

2) Johnson, E. A. and Rettger, L.: A comparative study of the nutritional requirements of Salmonella iyphosa, Salmonella pullorum and Salmonella gallinarum. J. Bact., 45, 127, 1943.

3) Johnson, E. A. and Rettger, L.: A comparative study of the nutritional requirements of Salmonella typhosa, Salmonella pullorum and Salmanella gallinarum. J. Bact., 41, 41, 1941.

4) Johnson, E. A. and Rettger, L.: A comparative study of the nutritional requirements of Salmonella pullorum, Salmonella gallinarum and Salmonella typhosa. J. Bad., 43, 103, 1942.

5) Burrows, W.: The nutritional requirements of the salmonellas. J. Inf. Dis., $64,145,1939$.

6) Burrows, W.: The nutritional requirements of salmonella. II. The formation of indole and tryptophane by the typhoid bacillus. J. Inf. Dis., 65, 134, 1939.

7) Burrows, W.: The nutritive requirements of the salmonellas. III. The typhoid bacillus. J. Inf. Dis., 70, 126, 1942.

8) Akiba, T. and Arai, I.: Mechanism of growth promoting action of tryptophane for S. typhosa. Jap. J. Exp. Med., 21, 7, 1951.

9) Curcho, M. G.: Mutation to tryptophane independence in Eberthella typhosa. J. Bact., 56, 374, 1948.

10) Bacon, G. A., Burrows, T. W. and Yates, M.: The effects of biochemical nutrition on the virulence of Bacterium typhosum: the loss of virulence of certain mutants. Brit. J. Exp. Path., 32, 85, 1951.

11) Cowie, D. B., Bolton, L. T. and Sands, M. K.: Sulfur metabolism in Escherichia coli, II. Competitive utilization of labeled and nonlabeled sulfur compounds. J. Bact., 62, 63, 1951. 